\title{
Antropologías Post-coloniales: la antropología islámica y la islamización del conocimiento en ciencias sociales
}

Silvia Montenegro UNR/CONICET
Desde hace unas pocas décadas ciertas intelectualidades "nativas" insisten en cuestionar la asociación entre la disciplina antropológica como un todo y lo que no sería más que su versión occidental. Algunos de tales emprendimientos no se construyen en las márgenes del mundo académico internacional sino que se desarrollan en los centros de investigación y programas de estudios que, en los países centrales, congregan a las llamadas "minorías".

En algún punto pueden ser vistos como discursos "reactivos", fuertemente cuestionadores de la mirada que occidente ha construído de sus "otros". Al analizarlos es posible hipotetizar que conforman miradas contra-orientalistas, si pensamos en la noción de orientalismo acuñada por Said para referirse a la relación entre conocimiento y poder con que occidente construyó los modos de ver y conceptualizar los mundos orientales (Said 1978). Encontramos en ese contexto una serie de antropologías, adjetivadas ahora según la dirección de un modelo más amplio a cuyo seno serían reintegradas. El proyecto de constitución de una antropología "islámica" ilustra ese proceso, en tanto supone insertar un conocimiento, el antropológico, en la matriz más amplia del pensamiento islámico.

A simple vista, podría parecer que estamos ante la pretensión de una versión religiosa, en este caso islámica, de la antropología. De hecho, el programa de una antropologia islámica se refiere, indirectamente y a su modo, a la relación entre ciencia y religión dentro de ciertas vertientes del islamismo; sin embargo, parece más fructífero buscar las pistas de estos emprendimientos en los discursos reactivos, críticos y complejos de cierta intelectualidad cuya trayectoria nos interesa señalar.

Tal vez podamos considerar que esa matriz de pensamiento se conforma a partir de una serie de presupuestos de discurso "pós-colonial" ${ }^{11}$. El linaje intelectual que la ilumina se remonta a las teorizaciones y a las propuestas "nativas" para construir las sociedades, después de las independencias frente a los poderes coloniales, en países donde el Islam comenzó a aparecer como una alternativa ideológica 
En el ámbito de las ciencias sociales, y de la antropología en particular, la idea de islamizar el conocimiento fue portada por ciertos estratos intelectuales del Islam, en su mayoría formados en universidades de occidente. El concepto ganó forma y fuerza a partir de la fundación de la Asociación de Cientistas Sociales Musulmanes. Actualmente, los tópicos de discusión de esta intelectualidad musulmana aparecen plasmados en publicaciones propias como el American Journal of Islamic Social Science (AJISC) que, desde 1984, edita conjuntamente el Instituto Internacional de Pensamento Islámico y la Asociación de Cientistas Sociales Musulmanes, simultáneamente en Washington, Malasia y Paquistán, pero cuja influencia, sin duda, extrapola esos límites territoriales. El propósito de AJISC es servir de puente entre la intelectualidad musulmana que reside y se ha insertado institucionalmente en universidades de occidente $y$ aquellos que se localizan en el mundo musulmán. Al mismo tiempo, busca unificar la información de las investigaciones sobre el Islam realizadas a nivel internacional, convocando y organizando congresos en universidades, especialmente americanas y canadienses.

La filiación institucional de los cientistas que allí publican es variada. Por un lado, encontramos un cuerpo de intelectuales que trabajan en la Universidad del Cairo, Egito, en Malásia, Paquistán y Emiratos Árabes. Muchos enseñan en universidades de "occidente", como la Oxford University, Universidad de California, Pennsylvania, etc., formando parte de centros de estudios sobre el Islam u Oriente Médio. No obstante, las publicaciones como el Americam Journal of Islamic Social Sciences o la Periódica Islámica están abiertas a "orientalistas" de renombre no musulmanes. Doctorados en ciencias sociales, antropología, ciencias de la comunicación y filosofía, esos intelectuales discuten el pasado y la actualidad del Islam, tanto fuera cuanto dentro de occidente, al mismo tiempo que debaten sobre la mirada tradicional de occidente sobre el mundo del Islam.

Esas "voces nativas" cuestionan el conocimiento disponible sobre el Islam producido por occidente y se refieren a la necesidad de re-escribir la historia, esta vez "desde dentro". Para eso sería necesario "islamizar" las ciencias sociales en sus diferentes ramas. ¿Qué significa ese programa? ¿Cómo es llevado a cabo dentro de la antropología y cuál es la significación general de ese proyecto?, es lo que trataremos en este artículo.

\section{LA ISLAMIZACIÓN DEL CONOCIMIENTO Y LA ASOCIACIÓN MUSULMANA DE CIENTISTAS SOCIALES}

Existe una figura central en el establecimento del programa que ha sido llamado "islamización del conocimiento", su nombre es Islamil Al-Faruqi. Su obra y su propia biografia muestran la compleja construccón de un encuentro intelectual entre el conocimiento occidental y la tradición islámica. Nacido en Palestina, en 1921, durante el mandato británico, recibe su educación en escuelas islámicas tradicionales. Con la fundación del Estado de Israel Al-Faruqi se exilia y recorre varios países, tanto dentro de occidente como del mundo musulmán. Primero se establece en 
el Líbano donde estudia en la Universidad Americana de Beirut, luego se traslada a Estados Unidos e ingresa a la Universidad de Harvard obteniendo su master en filosofia, en 1952 obtiene su doctorado en esa área en la Universidad de Indiana. Posteriormente se traslada a Egipto, donde entre 1952 y 1954 se desempeña como profesor en la prestigiosa Universidad Al Azhar, referente internacional del pensamiento islámico, en ese período también participa del Research Institute de Paquistán. Una de sus áreas de actividad académica fue la filosofía de la religión, ocupándose no sólo del Islam sino también de la realización de una serie de estudios sobre la ética cristiana, en la década del 60.

Más tarde, Al-Faruqi privilegiará la acción política, sobre todo a partir de su incorporación al Departamento de Religiones de la Syracuse University, donde forma la Asociación de Estudiantes Musulmanes de los Estados Unidos y Canadá, en 1962. En 1968 se transfiere al Departamento de Religiones de la Temple University. En pocos años su influencia y sus obras permean el campo intelectual de los musulmanes educados en occidente.

En 1971, Al Faruqi es el primer presidente de la recién fundada Asociación Musulmana de Cientistas Sociales, cargo que ocupa hasta 1976. La Asociación comienza a aglutinar a los intelectuales que completan sus estudios de posgrado en universidades de Estados Unidos y Canadá, es en ese momento que se forman los primeros foros de discusión y debate.

El American Journal of Islamic Social Sciences y otra revista académica llamada "Islamiyyat Al-Ma'arifah", dedicada específicamente a la teoría de la islamización del conocimiento, permiten rastrear, hasta el presente, el legado del programa de islamización inaugurado por Al-Faruqi.

La noción de "islamización del conocimiento científico" es anterior al emprendimiento de Al Faruqi, aunque fue él quien logró su institucionalización. Su origen se remonta a los escritos de Abu Salayman que, em 1960, presenta la noción de "islamización del conocimiento" juntamente con el concepto de "ciencias sociales islámicas", aplicado a su área de producción académica, las ciencias políticas. Pero, como dijimos, la sistematización y activación del proyecto se deben básicamente a Al Faruqi, como él mismo expresa en su discurso frente a la Asociación de Cientistas Sociales Musulmanes, en Indiana:

Tenemos por delante una tarea muy importante. Durante mucho tiempo tuvimos que contentarnos con las migajas que occidente nos daba. Estamos en el momento de hacer nuestra propia contribución original. Como cientistas sociales, debemos mirar para atrás y reformar nuestro entrenamiento a la luz del Corán y de la Sunna. Esto quiere decir que debemos considerar el modo en que nuestros padres predecesores hicieron su propia contribución al estudio de la historia, de las leyes y de la cultura. Occidente borró esa herencia y la colocó en un molde secular, ¿es pretender demasiado tomar este conocimiento e islamizarlo? (Al Faruqi 1972) ${ }^{2}$. 
Evidentemente, se trataba de iniciar el rescate de la tradición de clásicos del pensamiento musulmán y del delineamiento de un programa ambicioso para islamizar las ciencias sociales. En 1982 el concepto de islamización del conocimiento propuesto por Al Faruqi ya era conocido a través de publicaciones y debates y estaba concentrado casi exclusivamente en las ciencias sociales. La fundamentación del plan de islamización se basaba en un diagnóstico de crisis del mundo moderno musulmán, y esa crisis era conceptualizada como referida al desarrollo de las ciencias. La propuesta era nada menos que una nueva síntesis del conocimiento en el marco de una epistemología islámica, un proyecto que debería permitir a los musulmanes convertirse en partícipes activos de la vida intelectual.

Subyace al programa de islamización del conocimiento una toma de posición respecto a la introducción de nociones científicas secularizantes en las sociedades musulmanas, cuestión considerada generalmente indeseable por los sectores tradicionalistas religiosos. No se trataba de impedir la penetración del conocimiento de las ciencias sociales occidentales sino de tomar ese conocimiento e islamizarlo, impidiendo que entre en contradicción con el punto de vista islámico. Según Faruqi, el uso de herramientas, categorías y modos de análisis originados solamente en el occidente secular producía una desconexión con la realidad de las sociedades musulmanas y generaba incapacidad para respetar o vigilar las violaciones a la ética del islam. Faruqi era consciente del choque entre el tradicionalismo religioso encarnado por los estamentos religiosos y los reformadores que buscaban revitalizar el islam en las sociedades musulmanas y, ciertamente, se colocaba de lado de los segundos. Pero creemos que su programa buscaba explícitamente conformar ambos sectores. En primer lugar se refería a la necesidad de un retorno ético a los métodos de los primeros filósofos del islam, a la reavivación de los mismos, para luego reintegrar los métodos científicos de occidente circunscribiéndolos a los límites del Islam. De ese modo, un cuerpo de conocimiento nuevo, pero islamizado, no tendría por qué contrariar a sectores tradicionalistas.

El mismo Faruqi relata como su vida en Estados Unidos y el contacto con los estudiantes musulmanes, en los campus de las universidades norteamericanas, había producido ya hacia la década del 70 un cambio en su autopercepción: “Hace unos pocos meses yo era un palestino, un árabe y un musulmán. Ahora soy un musulmán que por casualidad es un árabe de palestina" (Ba-Yunus 1988:14). El colocar la pertenencia religiosa por encima de adscripciones nacionales o étnicas será fundamental en el desarrollo de su programa de islamización.

De acuerdo a su proyecto existían tres grandes consecuencias del imperialismo cultural de occidente sobre el mundo musulmán. Por un lado, la estagnación del conocimiento islámico era evidente en las madrasas (escuelas islámicas), éstas terminarían por decaer sino se tornaban innovadoras y más dinámicas. En segundo lugar, la educación moderna carecía de excelencia. Al ser "implantado" en los países musulmanes el conocimiento occidental, que sí producía resultados en los países occidentales, permanecía estéril y ritualista, con una falsa aura de progreso. Por último, estaba el problema de la dependencia de la intelectualidad musulmana de las ideas extranjeras, que se evidenciaba en los temas elegidos y las investigaciones emprendidas (Al-Faruqi 1982:34). 
Ilyas Ba-Yunus, destaca que el pensamiento de Faruqi debe ser entendido a partir de las consecuencias que los poderes coloniales plasmaron en el mundo islámico, sobre todo por medio de la secularización del conocimiento. De acuerdo con ese autor, el programa de islamización del conocimiento puede resumirse en la siguiente frase: “la unión de dos sistemas por medio de lo cual se espera que el conocimiento islámico arroje luz sobre el conocimiento moderno y secular del sistema islámico" ( Ba-Yunus 1988:19).

Podemos decir que, en todo caso, no se trataba de sacralizar las ciencias sociales y el conocimento en general, incluso porque AI Faruqi no definía al Islam como una religión sino como una forma de vida o una ideología. El programa como un todo proclamaba que era imprescindible islamizar las distintas ramas de las ciencias sociales, señalando la necesidad de una reforma metodológica y epistemológica que tenía un fuerte componente de reflexividad. Esto implicaba una especie de proceso de "estudiarse a si mismos" ya que ahora serían cientistas sociales musulmanes quienes debían establecer un puente entre esos dos conocimientos, en la tarea de estudiar el propio Islam y las sociedades musulmanes. Aquello implicaba retrotraerse a la tradición del Corán y de la sunnah, es decir, a la tradición de los libros sagrados, juntamente con la retomada del legado del pensamiento musulmán, aunado a un profundo conocimiento de la tradición de las ciencias sociales de occidente.

En 1986 Al-Faruqi fue asesinado en su residencia de los Estados Unidos junto a su esposa. Algunas publicaciones musulmanas de la época, conscientes de los efectos de la prédica de Faruqi, se atrevieron a dudar: $¿$ “la tragedia había sido perpetrada por los enemigos internos o externos del Islam" ? ${ }^{3}$. No obstante, el programa de islamización del conocimiento y también el influjo de la figura de Al-Faruqi en tanto "mártir del Islam”, estaban ya consumándose.

\section{LA ISLAMIZACIÓN DE LA ANTROPOLOGÍA}

Existen diversos emprendimientos de islamización en el campo de las ciencias políticas, de la economía y la sociología, aquí nos interesa destacar el caso de la antropología, refiriéndonos al proyecto de Akbar S. Ahmed, antropólogo paquistanés, doctorado en antropología por la Universidad de Londres, miembro del Centro de Estudios Asiáticos de la Universidad de Cambridge.

Sin dudas, Akmed es más conocido en el mundo académico de la antropología por sus trabajos sobre los Puktun, los análisis sobre orden y conflicto en las sociedades musulmanas y sobre el Islam en sociedades tribales, que por su papel entre la intelectualidad islámica ligada al programa de islamización del conocimiento ${ }^{4}$.

Sin embargo, Akbar Ahmed trazó un programa de islamización del conocimiento antropológico - en su obra Toward Islamic Anthopology - destacando que no es posible concebir la antropología apenas como una ciencia 
occidental, nacida del colonialismo, sino que debe ser también considerada como una tradición de pensamiento cuyo legado los antropólogos musulmanes podían remontar a los estudios de lbn Khaldun, a los viajes de lbn Battuta o a los estudios sobre las sociedades indianas de AI Biruni. Su libro no elude una definición de lo que sería una antropología islámica ni el delineamiento de la acción necesaria para lograr ese proyecto. Ahmed se refiere al nuevo lugar de los antropólogos frente a la urgencia de establecer un puente entre sus tradiciones culturales y su formación occidental (Ahmed 1986).

Como el mismo Akbar Ahmed señala, la islamización del conocimiento responde al modelo del Resurgimiento islámico (ibid:224). A esto podemos agregar que es solamente en este nuevo entendimiento del papel del Islam en las sociedades, impulsado por las ideas del Resurgimento, que esta idea de re-islamizar las ciencias sociales se torna plausible. No sería posible detenernos aquí en la caracterización de las corrientes del Resurgimiento Islámico, pero es útil recordar que desde los años 70 este amplio movimiento ha sido influyente en los países musulmanes. Procesos económicos, políticos y culturales, el boom del petróleo en los países del golfo, la revolución de Irán, la revitalización de las organizaciones musulmanas y el creciente sentido de identidad islámica entre intelectuales y estudiantes fueron algunos de los aspectos que marcaron los movimientos ideológicos de las últimas décadas. Uno de los aspectos más significativos del Resurgimiento islámico es que un creciente número de intelectuales musulmanes educados en occidente y residiendo en diferentes partes del mundo pretendieran llevar la perspectiva islámica hacia el interior de las ciencias sociales (Momin 1987).

La propuesta de islamización de las ciencias sociales supuso la reivindicación retrospectiva de otros clásicos, para trazar a partir de ellos una especie de "linaje paralelo" que otorgara originalidad al adjetivo "islámica", colocado a cada una de las ramas de las ciencias sociales.

\section{LA CENTRALIDAD DE OTROS CLÁSICOS}

La tradición intelectual del pensamiento islámico es profundamente rica. Analisando los linajes construidos por la intelectualidad musulmana ligada al programa de islamización de las ciencias sociales es fácil ver que aquí opera lo que J. Alexander (1990) denominó "centralidad de los clásicos", para referirse al lugar de ciertos autores clásicos en la teoría social. Evidentemente, la comparación sirve sólo como una analogía para indicar el rescate de la tradición intelectual islámica a través de la reivindicación de "otros" padres fundadores a cuyas ideas se retorna de forma casi obligatoria, generandose así esa especie de consenso discursivo que ordena y torna posible el debate.

Para Akbar Ahmed la antropología no es sólo una criatura de occidente o más específicamente del imperialismo 
occidental. Desde su punto de vista, los trabajos de lbn Khaldun fueron apropiados por algunos de los téoricos más influyentes de occidente, desde Karl Marx, Max Weber y Wilfredo Pareto hasta Ernest Gellner. Ahora bien, según el programa de las ciencias sociales islámicas lbn Khaldun es considerado el padre fundador de la sociología y de las ciencias de la história, de él se reivindican los estudios y tratados sobre la dinámica, ascención y caída de las civilizaciones, sus trabajos sobre crítica y filosofía de la historia y los estudios sobre historia mundial que habrían incluido la vida de los pueblos árabes, judíos, griegos, romanos, persas, la historia de Egipto y del norte de África ${ }^{5}$.

Se argumenta que fue Ibn Khaldun quien inauguró, en el siglo XIV, una metodología de las ciencias de la historia. Al mismo tiempo, se supone que por medio de la observación de la vida y de la dinámica de los pueblos inauguró también la sociología. Desde el punto de vista de Ahmed la tipología del liderazgo de Weber, la teoría de la circulación de las élites de Pareto y las teorizaciones de las sociedades musulmanas de Gellner contienen las huellas de la influencia de la obra de Khaldun, y no sólo de éste sino también de Al Biruni o lbn Battuta, entre otros (1986: 217).

Pero esto no es todo, entre las figuras clásicas reivindicadas por los intelectuales adheridos al programa de la islamización de las ciencias sociales la obra de Abul-Waleed Muhammad Ibn Rushd (1128-1198), conhecido como "Averros", permite situar el comienzo de las ciencias sociales en el mundo musulmán en el siglo XII. "El gran comentador", es visto de manera indiscutida como un clásico del pensamiento musulmán, valorándose sus comentarios y traducciones para el árabe de la filosofia aristotélica. Así, le cabe el lugar de ser uno de los filósofos musulmanes más importantes.

Sin embargo, la antropología sería incluso una disciplina anterior a la filosofía de Averros, Ahmed dedicó un artículo a destacar que Al Biruni (973-1048) era el "padre de la antropología", alegando que Kitab al Hind (libro de la India) fue uno de los primeros tratados sobre los pueblos de la India, resultado de una "observación participante" de esas culturas. No sólo la observación participante, como técnica por excelencia de la antropología, sería un "descubrimiento" de Al Biruni, sino también el uso del método comparativo implementado para establecer correlaciones con otras culturas conocidas de primera mano. Según Ahmed "casi mil años antes que C. Geertz o Malinowski Al Biruni había fundado la ciencia de la antropología", hecho probatorio de que tanto la antropología como la sociología no son ciencias nuevas u occidentales (Ahmed 1984) ${ }^{6}$.

La lista de padres fundadores continua con Ibn Battuta, que habría realizado "trabajo de campo" en el siglo XIV, por medio de sus viajes y descripciones de las etnias islamizadas del Africa. Para los intelectuales que promueven la idea de la antropología islámica su figura es fundamental ya que constituye una narración completa de un encuentro intercultural que testimonia las variantes locales de una religión universal.

En conjunto, los argumentos acerca de los precursores musulmanes de las ciencias sociales destacan la 
antiguedad de estas tradiciones, "antes que occidente", y del uso de las técnicas propias de la antropología así como de la teorización acerca del contacto intercultural en la observación de primera mano de otras culturas.

\section{LA CRÍTICA A LA ANTROPOLOGIA OCCIDENTAL}

En lo que respecta al desarrollo de la antropología occidental es importante señalar que la estructura del libro de Ahmed presenta dos partes bien delimitadas. Por un lado, encontramos un análisis de la tradición antropológica y; por el otro, la propuesta de la islamización de la antropología. Ahmed realiza un estudio detallado del desarrollo de la antropología tomando en cuenta sus orígenes, sus relaciones con otras disciplinas, deteniéndose largamente en los conceptos y teorías acuñados durante el encuentro colonial. Es en este último punto dónde situa lo que denomina el "marco teórico de la antropología occidental". Uno de los pasajes más interesantes resulta de su diagnóstico de crisis de la disciplina, se vale para ellos de una serie de títulos que se preguntan por el futuro de la disciplina, argumentando que son los mismos antropólogos occidentales los que temen por la desintegración disciplinar. A su ver, la antropología está atravesando por un estado de paralización en cuanto a la producción teórica, vinculado indirectamente a la desaparición de su objeto tradicional, los pueblos primitivos, pero también y, más que nada, por el surgimiento de los antropólogos nativos. Indirectamente podríamos leer aquí que su propia postura se enmarca en las propuestas nativas dispuestas a desafiar los usos y costumbres de la antropología occidental.

Ahmed desagrega uno a uno los principales puntos de análisis de la antropología occidental, refiriéndose con fina erudición a las diferentes corrientes. Al tomar el punto del análisis de la estructura social se centrará en la antropología británica, tomado las derivaciones durkheimnianas de Radcliffe-Brown y el funcionalismo de Malinowski, para mostrar posteriormente las "falencias" de la antropología marxista y los estragos del marxismo vulgar aplicado a las sociedades tradicionales. En lo que se refiere a las relaciones de parentesco y al análisis de las formas de organización política, Ahmed reseña los trabajos de Radcliffe-Brown, Evans-Pritchard y M. Fortes, no sin criticar lo que para él sería un excesivo acento en el "algebra del parentesco". El recorrido crítico por las escuelas sigue la sistematización de los grandes temas de la antropología, centrándose así en tópicos tales como: creencias, magia y religión; antropología económica y en el análisis del proceso de cambio social. La síntesis culmina argumentando la necesidad de demostrar en qué puntos la antropología occidental ha sido influenciada por la literatura orientalista.

En el diálogo que Ahmed entabla con lo que llama "antropología orientalista" parte, como es lógico, de las críticas de Said al orientalismo. El uso de términos como "mahometanos", ofensivo desde el punto de vista de los creyentes, no sería nada si comparado con las conclusiones de trabajos que Akmed cita como impregnados de retórica 
orientalista. Uno de los blancos principales es Frederik Barth con quien entabla una crítica abierta respecto del estudio de los Pukthuns, tema en el que el mismo Akmed tiene una larga trayectoria. Desde su punto de vista, Barth tiene una visión hobbesiana de las sociedades musulmanas, es decir, "la vida musulmana es pobre, dura, bruta y breve y se vincula a la violencia, el ataque y el cálculo". Afirma Ahmed que un discípulo de Barth da un paso más allá que su maestro postulando que la sociedad de los Pukthuns es similar a la mafia, ignorando todo el sistema cultural, el folklore y el desarrollo de esa sociedad por más de cinco siglos, al "reducirla a los modernos gánster de la civilización occidental" (Ahmed 1986:215).

Como queda claro en la postura de Ahmed la antropología islámica aparece como una crítica al orientalismo antropológico:

Cuando los intelectuales atacan al profeta y a los fundamentos del Islam o cuando los antropólogos occidentales ecuasionan sociedades musulmanas con la mafia, ¿deben los musulmanes esconder sus cabezas en la arena y hacer como que no oyen esas voces? ¿Deben simplemente rechazar las investigaciones occidentales -o no musulmanasprohibiendo que lleguen a sus países? Si es así ¿deben ellos construir una cortina de hierro intelectual alrededor de sus sociedades? ¿O deben argumentar, sintetizar y entonces preparar la réplica en los términos de una antropología islámica? (ibid. p. 217).

Es en este punto donde la propuesta de Akmed se torna netamente político-religiosa. El problema de la antropología radicaría en su larga tradición de injurias hacia el Islam, los antropólogos habrían tenido un papel activo en la reificación de los dos mitos que más afectan al mundo musulmán: el referido al estatuto de la mujer (como carente de derechos, junto a la idea de la existencia generalizada de la poligamia en las sociedades musulmanas); siendo el segundo mito el del despotismo político en las sociedades musulmanas. Incluso Ahmed dirá que "simples costumbres religiosas" musulmanas fueron exageradas hasta el ridículo por la antropología, a propósito critica un número del Current Anthropology dónde se entabla una polémica sobre la prohibición musulmana de comer carne de cerdo. Para Akmed, la discusión se entabla en un tono que caricaturiza y satiriza el tema, que acaba siendo utilizado como símbolo para postular la división entre occidentales - consumidores de carne de cerdo - y musulmanes - no consumidores de carne de cerdo. (ibid.:219).

En síntesis, lo que aquí se critica no es tanto el cuerpo de monografías producidos por la antropología occidental sobre sociedades musulmanas, sino los intereses políticos que serían subyacentes y funcionales a la dominación occidental y la colaboración de la antropología para difundir visiones de mundo que generan estereotipaciones de los musulmanes. 


\section{LA ANTROPOLOGIA ISLÁMICA COMO PROYECTO}

La antropología islámica según la definición de Akbar Ahmed no excluye a los antropólogos no musulmanes pero sí a quienes desconocen los principios del Islam:

Podemos definir a la antropología islámica como el estudio de los grupos musulmanes realizado por investigadores vinculados a los principios universales del Islam: humanidad, conocimiento y tolerancia, relacionando los estudios de pequeños pueblos tribales a los marcos históricos e ideológicos más amplios del Islam, entendiendo al Islam no como teología sino como sociología (Ahmed 1987:56).

Se trata de un proyecto correctivo sobre la antropología occidental, que asume la tarea de enmendar las "distorsiones" y cuestionar la reproducción de ideas consagradas por la antropología orientalista. Pero esto no parece ir en contra del gran proyecto constitutivo de la antropología, Ahmed supone que la antropología islámica trata también de "ser capaces de entendernos a nosotros mismos a través del entendimiento de otras culturas" (ibid.:13).

Lo que queda claro es que para Ahmed son los antropólogos musulmanes los que tienen la última palabra sobre el conocimiento del Islam y las sociedades musulmanas. Las recomendaciones que cierran su proyecto de construcción de una antropología islámica dan cuenta de la pretensión de su reescritura antropológica. Veamos algunas de sus indicaciones: debería realizarse una biografía sociológica del profeta Mahoma preparada por musulmanes, sin que ésta sea ni demasiado académica ni demasiado simplista7. Sería necesario escribir un manual de antropología de alto standard para su traducción a las principales lenguas del mundo musulmán, éste debería incluir sesiones para cada área cultural. Podrían producirse monografias sobre cada región islámica para el uso en colegios y universidades del mundo musulmán. Los antropólogos musulmanes deberían comenzar a visitar los países islámicos para organizar proyectos de investigación de largo alcance y duración. Por último, debería extraerse el material etnográfico y antropológico contenido en la obra de los pensadores musulmanes clásicos, realizando una compilación de una serie de volumenes que sirvan como marco de análisis para los trabajos futuros (Ahmed 1986: 229).

Es claro que la antropología islámica no puede ser más que un proyecto y una propuesta de esa intelectualidad nativa. Su papel parece vincularse más al ejercicio de un discurso contra-orientalista que a constituirse como un nuevo campo de conocimiento iluminado por principios metodológicos y epistemológicos islámicos, sobre los que no parece existir demasiado acuerdo. En un interesante ensayo sobre la relación entre la antropología producida en el norte y en el sur, J. Llobera se refiere en un plano más amplio al problema que aquí tratamos, la distinción y relaciones entre discurso nativo y discurso foráneo. Ciertamente, para la antropología se trata de una problemática 
nueva, anteriormente los nativos no escribían y ahora que lo hacen parecen cuestionar aquello que no ha sido escrito por ellos, esto podría reconocerlo el propio Ahmed. Llobera, que es implacable en su crítica a todo lo que le sugiera antropología posmoderna o cuestionamiento de las bases científicas de la antropología, no deja de reconocer que la distinción actual entre discurso nativo y discurso foráneo ha perdido vigencia, en favor de una relación simbiótica que actualmente relaciona a ambos discursos. Ha sido puesta en tela de juicio la idea de la distanciación como requisito para la práctica antropológica. El argumento de que la no pertenencia a la propia cultura, de hecho o por "extrañamiento", es un requisito metodológico o una condición sine qua non de la investigación etnográfica, hoy es vista como una argucia retórica destinada a justificar situaciones de hecho de quienes se han arrogado el derecho de ser traductores-portavoces culturales de la sociedad que han estudiado (Llobera 1990:11). Sin dudas, cada vez es más difícil sostener la tajante división entre observadores y observados o, incluso, construir un conocimiento sobre otros culturales que ahora participan más activamente en el cuestionamiento de la manera en que son "construídos".

Pero el discurso nativo no representa una forma pura e intocada de referirse a sí mismos, parece haber consciencia de ello en la propuesta de Ahmed si consideramos que el problema del discurso nativo parece ser su contaminación con el discurso foráneo. De ahí que, una vez islamizada, la antropología esté destinada a tender puentes entre la visión de mundo islámica y la occidental.

Resulta interesante que algunas de las críticas a Ahmed provienen de su propio círculo de intelectuales nativos, de otros que como él, aunque con menos prestigio en el campo de la antropología occidental, pretenden islamizar el conocimiento. El antropólogo indiano A. Momin señala críticas muy asertadas al programa de islamización de la antropología proyectado por Ahmed.

En principio, Momin (1989) considera que actualmente nadie estaría dispuesto a afirmar la neutralidad valorativa de las ciencias sociales, por lo cual sería redundante acusar a la antropología occidental de no tomar la neutralidad como artículo de fe; pero lo que más parece preocupar a Momin es la parcialidad con que Ahmed ha reseñado la tradición antropológica, ateniéndose básicamente a la antropología británica y sin hacer una sola mención a Boas y al particularismo histórico. Aunque no se explaya sobre ese punto, es evidente que tener en cuenta la impronta del relativismo cultural de la antropología cultural norteamericana hubiese resultado en un balance menos duro respecto de la trayectoria de la antropología occidental. Nada parece criticar Momin a las "buenas intenciones" que conllevaría todo proyecto de islamización del conocimiento, su objeción es por lo vaga y fragmentaria que le resulta la propuesta de Ahmed y por la desconección que encuentra entre la crítica a la antropología occidental y la propuesta para sentar las bases de la antropología islámica. Momin ofrecerá un modelo alternativo, no mucho más claro que el que critica 
ni tampoco más estructurado. Para decirlo de otro modo, hay más de lo mismo en su lenguaje anti-orientalista y en su apelo a la necesidad de "corregir" las "distorsiones" creadas por la antropología, pero lo interesante es que da un paso más allá que Akmed. En primer lugar, consigue señalar el "peligro" de toda propuesta nativa, por lo menos teniendo en cuenta cómo puede ser recepcionada en los medios académicos; en segundo lugar, vincula la antropología islámica al proyecto de la antropología posmoderna. En su visión, sería deseable evitar una interpretación doctrinaria y dogmática de la adquisición del conocimiento, en tanto el punto de vista islámico no debe ser entendido como solipcista o xenófobo. Por otro lado, la antropología islámica es presentada por Momin como un capítulo o una contribución a los procesos de transformación que en la disciplina viene realizando la irrupción de una antropología posmoderna. Puntualmente, la antropología islámica se suma a tres procesos en curso: la "des-occidentalización" de la antropología, la afirmación de abordajes holísticos y la crítica a la tradición eurocéntrica:

Con la emergencia de la etnografía indígena y las tradiciones nacionales de las antropologías del tercer mundo, el proceso de des-occidentalización ya ha comenzado. La antropología islámica puede realizar valiosas contribuciones a este proceso para lograr el surgimiento de una ciencia del hombre genuinamente universal. Historicamente el Islam ha jugado un papel clave en el entendimiento y la integración intercultural. La antropología islámica tiene la posibilidad de llevar a cabo esta misión histórica (Momin 1989:152).

Fuera de la declamación de principios la antropología islámica parece un proyecto incierto. La propuesta de Momin ofrece mayor claridad, no en el significado de lo que sería el proyecto de una antropología islámica pero sí en el lugar que pretende ocupar y en la definición de los procesos que parece celebrar dentro del desarrollo de la disciplina. La problemática ha seguido como un debate interno de la intelectualidad musulmana, hasta ahora no parece poder plasmarse en un programa circunscripto. Como señala Nasr, otro intelectual que apuesta a la islamización y que realiza una crítica endógena, lo que no existe es una clara determinación sobre el significado del adjetivo "islamizar". Sería conveniente, entonces, esclarecer primero los fundamentos de una visión de mundo musulmana para discernir su relación con los presupuestos filosóficos que subyacen a las ciencias sociales de occidente. Si bien Nasr consigue mostrar la falta de acuerdo básico sobre la definición de la "visión del mundo islámica", no logra ir más allá de esbozar una intención cuando afirma la necesidad de una tarea epistemológica mediante la cual puedan discernirse las premisas básicas de las modernas ciencias sociales, para "identificar aquello que sea compatible con la visión islámica del mundo, separando los presupuestos que puedan ser islamizados para proceder a la elaboración y operacionalización de una perspectiva islámica sobre las ciencias sociales" (Nasr 1991:396). 
La antropología desde su origen estuvo atravesada por la tensión constitutiva entre el hallazgo de las semejanzas y la explicitación de las diferencias culturales. Uniformidad y diversidad fueron el par complementario en el que las diferentes perspectivas hicieron equilibrio. La valorización de las diferencias ha variado de acuerdo a la dosis de euro/etno centrismo y relativismo cultural que las distintas corrientes estuviesen dispuestas a admitir. El proyecto de una antropología islámica está claramemte asentado en una opción por exaltar las diferencias, en la sugerencia de que existe una inconmensurabilidad primera entre el "punto de vista islámico" y el occidental y sólo una posibilidad segunda de diálogo intercultural. Como programa, supone la dificultad, no asumida, característica de todo discurso contra-orientalista: el volverse el reverso de lo que cuestiona. El límite entre la crítica bien fundada a la tradición antropológica y el "occidentalismo" es sútil. El problema del occidentalismo es invertir el orientalismo y homogeneizar gran parte del conocimiento producido sobre el Islam, reduciéndolo al disfraz de estrategias de dominación y "desnaturalización" de los nativos. No se trata de la vieja discusión de los 70 anclada en la denuncia de la complicidad entre antropología y colonialismo, sino de las supuestas transformaciones que la propia voz de los nativos iría a imprimir en la disciplina. Como dijo Adam Kuper (2001:257), refiriéndose a la antropología posmoderna, el problema es el de la legitimidad, ¿Quién puede hablar por el otro?, si sólo la identidad confiere la autoridad necesaria para hablar, entonces, sólo podrían hacerlo quienes declaren un origen compartido con las víctimas: "esta oposición maniquea entre nativos y colonialistas, entre oprimidos y opresores, también puede imponer una uniformidad fáctica en todos los pueblos poscoloniales, esencializándolos, presionándolos para que representen el papel de una víctima estereotipada en una especie de Pasión occidental" .

La construcción de una antropología islámica puede comprenderse en el marco de la creación de un discurso identitario de autenticidad, quienes lo proponen son nativos singulares, aquellos que han conocido "por dentro" la vida en occidente. El proceso de "des-occidentalización" de la antropología puede, en cierto modo, ser una realidad. Como tal, supone el trazado de nuevos linages, la consagración de otros padres fundadores y toda una empresa en estado embrionario. llustra, sin embargo, lo que hace unas décadas es corriente, las "miradas externas" estan cada vez más obligadas a dialogar con "miradas internas". Los "conceptos de experiencia próxima" de los que hablaba C. Geertz8 para referirse al punto de vista del nativo se entrecruzan cada vez más con los "conceptos de experiencia distante", mediante los cuales el antropólogo torna comunicable la interpretación de los otros culturales.

Silvia M. Montenegroé Doutora em Sociologia pelo Instituto de Filosofia e Ciências Sociais da Universidade Federal do Rio de Janeiro, professora do Departamento de Antropologia da Universidad Nacional de Rosario e Pesquisadora do Consejo Nacional de Investigaciones Científicas y Técnicas - CONICET (Argentina). 


\section{NOTAS}

1 Para una problematización sobre el discurso post-colonial, así como un análisis de los significados de colonial y post-colonial, imperialismo y colonialismo, ver Willians, P. (1994).

2 La traducción es nuestra, en todos los casos.

3 Nota aparecida en Muslim Journal, Chicago, Vol. 13, No. 33, June 10, 1988, p. 6.

4 Algunos de los numerosos trabajos de Akbar Ahmed: 1980. Pukthun Economy and Society: Traditional Structure and Economic Development in a Tribal Society. London: Routledge and Kegan Paul; 1983. Islam in a Tribal Societies: from the Atlas to the Indus. London: Routledge and Kegan Paul; 1976. Millenium and Charisma Among Pathan: a critical essay in Social Antropology. London: Routledge and Kegan Paul; 1995. "Ethnic Cleasing: a Metaphor for our Time?". Ethnic and Racial Studies 18 (1).

5 Ver Zahoor, A. 1999. Muslim Scientists, 700-1500. Virginia: International Institute of Islamic Thought.

6 Ver A. Ahmed (1984).

7 Cabe recordar que una de las más destacadas biografías de Mahoma fue realizada por el orientalista francés y sociólogo marxista Maxime Rodinson. En su libro Rodinson afirmaba que el Corán había sido escrito por Mahoma, hecho que le valió la crítica e incluso la prohibición en algunos países musulmanes. Consultar Rodinson, Maxime. 1980. Muhammed. New York: Pantheon Books.

8 Hago referencia al conocido texto sobre el punto de vista del nativo, donde C. Geertz (1994) consigue señalar el complejo manejo que el antropólogo realiza de los conceptos de experiencia próxima y distante, de las categorías nativas y las propias de la disciplina. 


\section{REFERÊNCIAS BIBLIOGRÁFICAS}

AHMED, Akbar. 1986 "Toward Islamic Anthropology”. The American Jornal of Islamic Social Sciences 3(2) 181-230. 1987 Toward Islamic Anthropology: Definition, Dogma and Directions. Lahore: Vanguard Books. . 1984. "Al-Biruni: the First Anthropologist". London: Royal Anthropological Institute News.

AL FARUQI, Ismail. 1982. Islamization of Knowledge, general principles and work plan. Virginia: International Institute of Islamic Thought. . 1972 "Presidential Address". Virginia: The Association of Muslim Social Scientists.

BA-YUNUS, Ilyas. 1988. "Al Faruqi and Beyond: Future Directions in Islamization of Knowledge" The American Jornal of Islamic Social Sciences 5(1): 13-28.

GEERTZ, Clifford. 1994. "Desde el punto de vista del nativo: sobre la naturaleza del conocimiento antropológico" In Conocimiento local. Barcelona: Paidós.

KUPER, Adam. 2001. “Un mundo feliz” In Cultura, la versión de los antropólogos. Barcelona: Paidós.

LLOBERA, Joseph. 1990 "Excursus: el imperialismo cultural del Norte" La identidad de la antropología. Barcelona: Anagrama.

MONTENEGRO, Silvia. 2000. Dilemas Identitarios do Islam no Brasil. Tese de doutoramento. Rio de Janeiro: Universidade Federal do Rio de Janeiro.

MOMIN, A. 1989 "Islamization of Anthropological Knowledge". The American Jornal of Islamic Social Sciences 6(1): 143-154. 1987. "On Islamic Fundamentalism: the Genealogy of a Stereotype". Hamdard Is/amicus 10(4):35-46.

NASR, Seyyed. 1991. "Islamization of Knowledge: a critical overview”. Islamic Studies 30(3):387-400.

SAID, Edward . 1978. Orientalism. New York: Vintage Books.

WILLIANS, Patrick. 1994. Colonial Discourse and Post-colonial Theory. New York: Columbia University Press. 
Antropologías Post-Coloniales: la antropología islámica y la islamización del conocimiento en ciencias sociales RESUMEN

Este artículo analiza el discurso de las antropologías poscoloniales, construidas "desde el punto de vista de los nativos". Se retrata el caso específico del proyecto de una antropología islámica, según la propuesta del antropólogo paquistaní Akbar Akmed. Se afirma que fue en el contexto político y cultural de las ideas del Resurgimiento que se creó la Asociación de Cientistas Sociales Musulmanes en Estados Unidos, institución que desarrolló un programa de "islamización del conocimiento" inspirado en las ideas de Ismail Al-Faruqi. Dentro de la antropología fue Akbar Ahmed quien lideró ese proyecto plasmado, luego, en su libro Hacia una antropologia Islámica. Posteriormente el texto sugiere que el proyecto de una antropologia islámica incluye: a) una critica preliminar a la historia de la antropología en occidente; b) el argumento de la existencia de antropologías no occidentales basadas en otras tradiciones culturales, tales como el pensamiento islámico. La antropología islámica permite analizar las ambiguedades y desafios de un proyecto intelectual y político postcolonial que cuestiona y desdibuja las fronteras entre observadores y observados.

PALABRAS-CLAVE: postcolonialismo, tradición, Islam, intelectuales, antropología.

\section{Post-Colonial Anthropologies: Islamic anthropology and the islamization of knowledge in the Social Sciences}

\section{ABSTRACT}

This article analyzes the discourse of the postcolonial anthropologies, constructed "from the native's point of view". It depicts the specific case of the project of an Islamic anthropology, according to the proposal of Pakistani anthropologist Akbar Ahmed. It argues that it was within the political and cultural context of the Islamic Ressurgence ideologies that the Muslim Association for the Islamic Social Sciences was founded in the United States. This institution developed a program for the "islamization of knowledge" that was inspired in Ismail Al-Faruqi's ideas. Akbar Ahmed was the leader of this project within anthropology, shaping it in his book Toward Islamic Anthropology. The article also suggests that the project of an Islamic anthropology includes: a) a preliminary critique of the history of anthropology in the West; b) arguing for the existence of non-western anthropologies, based in "other" cultural traditions, such as Islamic thought. Islamic anthropology allows analysis of the ambiguities and challenges of an intellectual and political postcolonial project that questions and redraws the borders between observers and observed. KEY WORDS: post-colonialism, tradition, Islam, intellectuals, anthropology. 